Accelerator Division

Alternating Gradient Synchrotron Department

BROOKHAVEN NATIONAL LABORATORY

Upton, New York 11973

Accelerator Division

Technical Note

AGS/AD/Tech. Note No. 332

\title{
EDDY CURRENTS IN THE TRANSITION JUMP QUADRUPOLE VACUUM CHAMBERS
}

A. Feltman, J. Funaro, I. Ratner, W. van Asselt, P. Yamin November 15,1989

\section{Introduction}

A fast transition jump is being installed in the AGS. Quadrupoles located in the "17" straight sections of the A, C, E, G, I, and $\mathrm{K}$ superperiods will be excited with a $60 \mathrm{msec}$ risetime. This will raise the AGS transition energy by about $3 \mathrm{GeV}$. The transition energy will then be abruptly lowered during a $500 \mu$ sec deexcitation as the AGS itself passes through transition. The effect of these manipulations will be to speed up passage through transition by a factor of 30 to 100 if the magnetic fields in the quaddrupoles follow the excitation currents. This will drastically lower beam losses at this inherently unstable point. However, eddy currents induced in the vacuum chamber by the rapid de-excitation will reduce the amount of speed up. The purpose of these studies was to investigate the effects of eddy currents in the vacuum chamber on the pulsed magnetic field in a transition jump quadrupole.

\section{Procedure}

A simplified electrical schematic is shown in Figure 1a, and the mechanical arrangement is illustrated in Figure 1b. However, a prototype of the GTO switch which will be used in final installation was used for these tests. The quadrupole was energized to $3000 \mathrm{~A}$ by closing the switch (since $\mathrm{R} \gg \mathrm{r}$, little current flows in resistor). Upon opening the switch, the current was diverted to the bypass resistor and the quadrupole field decayed. An air core pick-up coil was placed in the magnet, about 1" from a pole tip, and the voltage induced in this coil during the decay was displayed 
on an oscilloscope. The mechanical configuration was such that the coil did not have to be disturbed in order to change the 2'-3' sections of vacuun pipe which were used in these tests.

\section{Results}

Figure $2 \mathrm{a}$ is a photograph of the oscilloscope showing current in $R$ and the coil voltage with no vacuum pipe. The pick-up coil (which is sensitive to $\mathrm{dB} / \mathrm{dt}$ ), gives a maximum output of $6.210 \mathrm{~V}$ at no delay, $\Delta$, after $(\mathrm{di} / \mathrm{dt})_{\max }$. Figure $2 \mathrm{~b}$ shows similar data, but for a $0.125 "$ aluminum pipe. The maximum coil output is $0.550 \mathrm{~V}$, which occurs 1,000 $\mu$ secs after the maximum di/dt. Table I summarizes all the data which we have taken.

\section{TABLE I}

Eddy Current Data

Pipe Material

Air

$0.020 "$ Inconnel

0.025 " Stainless

$0.062 "$ Stainless

$0.125 "$ Aluminum
$\mathrm{V}_{\max }(\mathrm{V})$

$$
\begin{aligned}
& 6.210 \\
& 5.57 \\
& 4.70 \\
& 4.24 \\
& 0.55
\end{aligned}
$$

$$
\mathrm{V}_{\max } / \mathrm{V}_{\max } \text { air }
$$

1.0

0.90

0.76

0.68

0.09
$\Delta(\mu$ secs $)$

$$
\begin{array}{r}
0 \\
0 \\
50 \\
100 \\
1000
\end{array}
$$

\section{Conclusions}

We conclude that the use of the present AGS vacuum chambers, which are 0.062" stainless steel, will degrade the speed of the transition jump by approximately $32 \%$. This is acceptable for the short term. However, in order to achieve the maximum benefits from the system, it would be desirable to go to a thin Inconnel chamber.

\section{Acknowledgments}

We would like to thank $\mathrm{E}$. Rodger and $\mathrm{K}$. Welch for supplying some of the vacuum chambers. The design of the GTO pulser is due to $\mathrm{K}$. Hughes. 
$-3-$
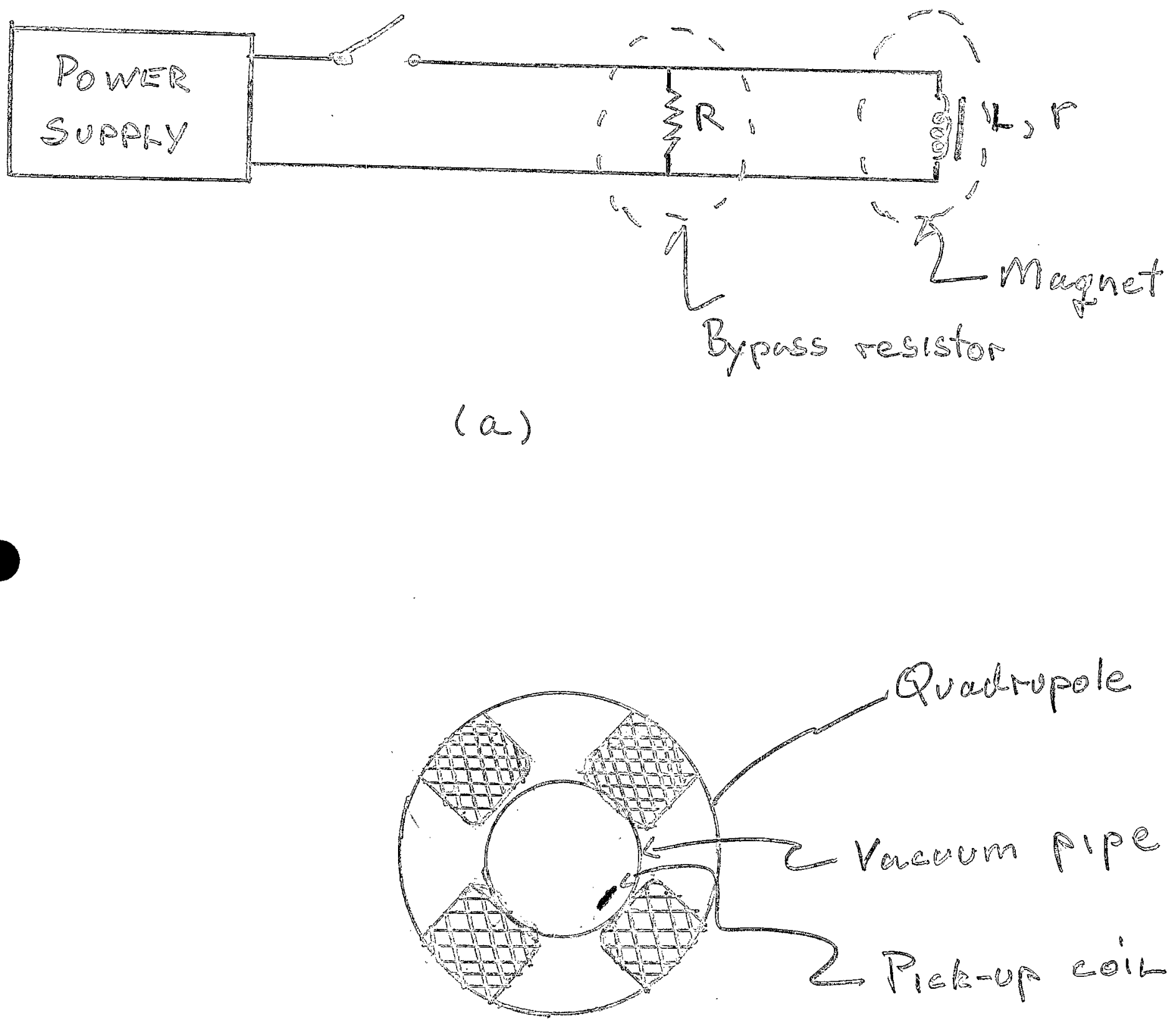

(b) 
$-4-$
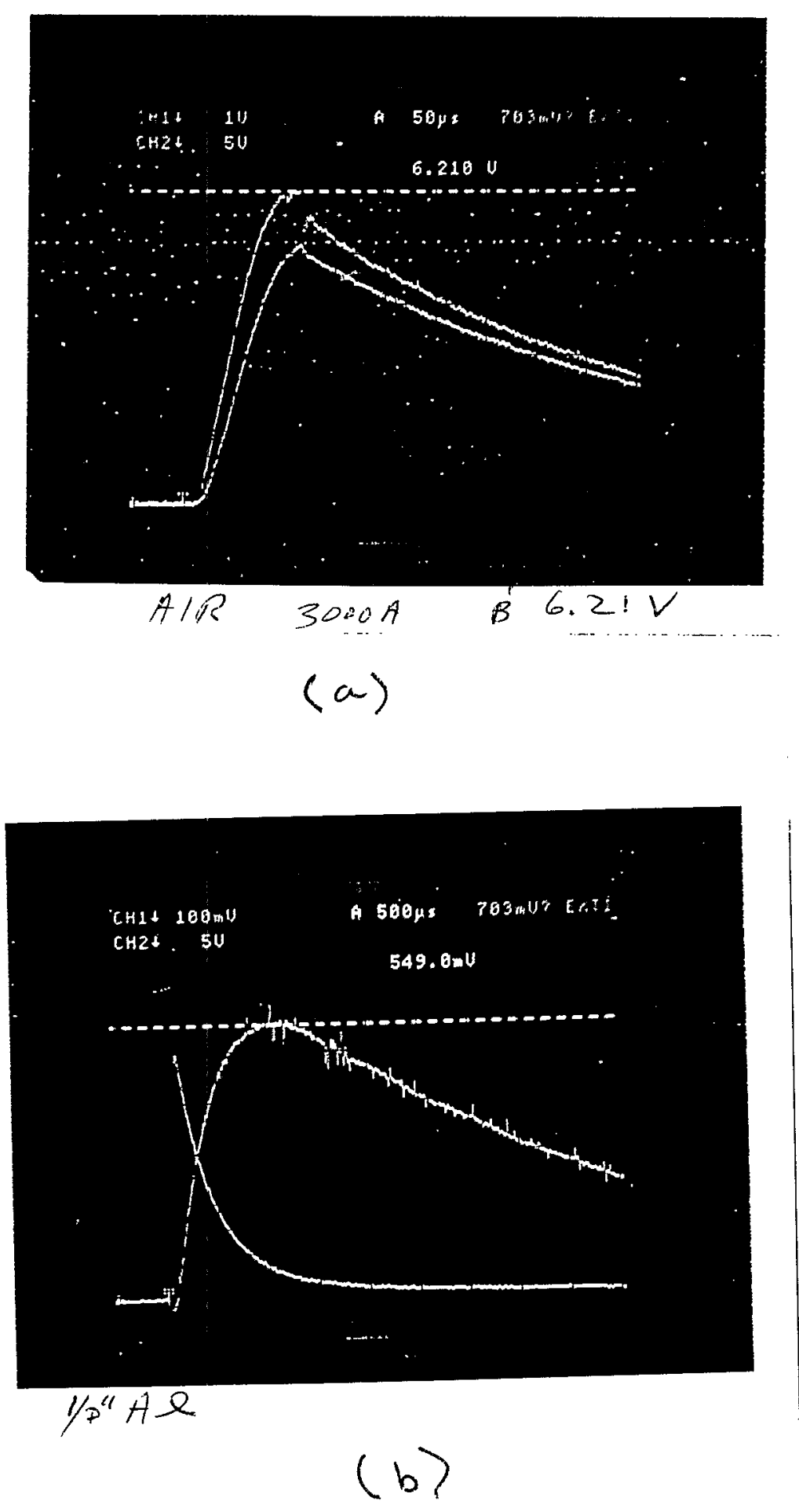

$$
\text { Fig. } 2
$$

